\title{
DETERMINAÇÃO, HISTÓRIA E MATERIALIDADE
}

\author{
DETERMINISM, HISTORY AND MATERIALISM
}

\author{
Virgínia Fontes $^{1}$
}

Resumo O ensaio critica algumas modalidades de determinismo atualmente dominantes, fugindo do pensamento aleatório ou pós-moderno. Procuramos contribuir para a explicação objetiva, porém sensível, do mundo, de modo a manter aberta a intervenção efetiva e consciente no processo histórico. $\mathrm{O}$ argumento apresenta a contraposição paradoxal e dolorosa entre determinismo econômico e uma liberdade amputada que o acompanha e, em seguida, mostra como a reflexão marxiana permite superar os impasses nos quais recaíram tanto os deterministas naturalistas quanto os antideterministas pós-modernos. Essa superação exige a demonstração da historicidade constitutiva do processo de trabalho, tanto no seu viés ontológico (Lukacs) quanto no viés histórico (Marx), apontando para a materialidade efetiva das relações sociais como forma de distribuição dos seres singulares no conjunto das atividades da produção de sua existência social. Concluímos mostrando como a determinação, em Marx, não é redutora e, portanto, não repousa sobre um econômico entificado.

Palavras-chave Marx; determinismo; historicidade; determinação; trabalho.
Abstract The article criticizes some currently dominant modalities of determinism, distancing itself from randomized and post-modern thinking. We look to contribute to the sensitive objective explanation of the world in order to keep effective intervention open and conscious in the historical process. The argument presents a paradoxical and painful contrast between economic determinism and a restricted freedom that accompanies it, and then shows how Marxist thought allowed them to overcome the impasses in which both the deterministic naturalists, as well as the postmodern anti-determinists had found themselves. This step requires the demonstration of the development of the work process, in its ontological view (Lukacs), as well as the historic view (Marx), pointing to the effective materialism of social relations, as a means of distribution of singular beings together with the activities of production of its social existence. We conclude by showing how determination in Marxism is not simplistic, and therefore, is not based on an economic truism.

Keywords Marxism; determinism; history; determination; work. 


\section{O problema}

O objetivo deste trabalho 2 é criticar algumas das modalidades de determinismo atualmente dominantes, sem recair em um pensamento aleatório ou pós-moderno. Os diversos pós-modernismos, ao tornarem todos os elementos equivalentes, interdizem, ao mesmo tempo, a explicação do mundo e a intervenção efetiva e consciente no processo histórico, embora eventualmente possam contribuir para a compreensão de certas sensibilidades, mais ou menos difusas.

Parto da suposição de que a compreensão histórica supõe um duplo e simultâneo movimento, 'explicar' e 'compreender'. Explicar exige identificar as relações e conexões fundamentais dos fenômenos sociais, cuja objetividade se expressa na própria materialidade da organização social, isto é, na distribuição dos seres sociais em classes sociais, estabelecendo determinações efetivas, porém maleáveis. Por serem formas de organização social, podem ser mais ou menos rígidas, porém não envolvem um determinismo naturalizante, seja de cunho biológico ou psicológico. Compreender implica apreender e entranhar-se dos sentidos e significados, muitas vezes contraditórios, e mesmo antagônicos, que atravessam a experiência da vida social e plasmam sociabilidades diversas. A contraposição entre explicar, conhecer ou saber e compreender, sentir ou afetar-se atravessa as ciências sociais, ao menos desde Weber (1992), que enfatiza fortemente o elemento compreensivo em detrimento do explicativo.

Diversos autores avançaram na superação dessa dicotomia entre objetividade e subjetividade, trabalhando-as como contradições vivas, em processo e não como formas duais cristalizadas. Como exemplos de análises mais densamente históricas, podemos apontar o próprio Marx, ao tratar o 'fetiche da mercadoria', ou Edward P. Thompson, ao procurar explicar o processo histórico através da apreensão das formas de consciência experimentadas pela classe trabalhadora (Thompson, 1987). Vale aqui relembrar, ainda, a já clássica citação de Gramsci, um dos autores lidos por Thompson:

O elemento popular 'sente', mas nem sempre compreende ou sabe; o elemento intelectual 'sabe', mas nem sempre compreende e, menos ainda, 'sente'. Os dois extremos são, portanto, por um lado, o pedantismo e o filisteísmo, e, por outro, a paixão cega e o sectarismo (Gramsci, 2001, p. 221-222).

Inscrevendo-me nessa tradição, procuro neste trabalho estimular uma reflexão sobre o fundamento central das formas de determinação históricas, derivadas da própria existência das relações sociais que configuram a existência humana, e que, por seu turno, moldam a maneira pela qual diferentes sociedades se relacionam com a natureza. Para isso, é necessário en- 
frentar o rígido determinismo econômico - e seu corolário quantitativista e segmentador - que caracteriza o capitalismo desde seus primórdios, determinismo exacerbado na atual conjuntura internacional e que tende ainda a se expandir. Tal determinismo é insuportável intelectual e humanamente e, por isso, se apresenta emparelhado com uma suposição de liberdade que o nega e reitera.

Para a superação dos determinismos, o desafio permanente consiste em reatar o elo entre a reflexão histórica, os grandes temas trazidos pela dialética e a forma contemporânea do capitalismo. Precisamos sempre pensar a conexão entre o encaminhamento de soluções para problemas concretos e a exigência de compreender/explicar processos sociais de amplo espectro, totalizantes, cuja dinâmica de transformação é interna e nos quais as consciências desempenham papel fundamental. Não se trata apenas de resolver problemas de forma imediata, mas de ser capaz de enfrentar desafios múltiplos e variados, de recolher do conjunto da experiência acumulada elementos que permaneçam abertos para a percepção e a construção de alternativas históricas radicalmente diversas daquelas já experimentadas. Urge pensar as condições de superação do capitalismo, explorando e ampliando as potencialidades humanas historicamente já entreabertas, recuperando e mantendo os elementos emancipadores que diferentes sociedades e formas de ser descortinaram ao longo do processo histórico e que, na atualidade, sobrevivem avassaladas pelo capital em escala mundial.

\section{Determinismo e liberdade amputada}

Que os opostos 'determinismo' e 'liberdade' se reúnam de maneira aparente não é de estranhar: desde o jusnaturalismo, consolidado, sobretudo, por Hobbes e Locke, a cristalização de uma natureza humana possessiva (Macpherson, 2004) exige a castração da liberdade de todos pelo Estado (quer seja absolutista, como em Hobbes, quer seja liberal, como em Locke e Montesquieu) em prol da garantia e conservação de um certo tipo de propriedade.

A lógica da acumulação de capital, de fato, impõe essa duplicidade, tanto intelectual, quanto prática e afetivamente. O determinismo econômico evocado pelos proprietários de recursos sociais de produção, em especial na figura idealizada do dinheiro que move o trabalho - fundado numa suposta natureza humana pelo pensamento liberal - exige liberar a população de todas as demais formas 'arcaicas' da vida social, promovendo socialmente seres livremente disponíveis de sua própria necessidade biológica de existir e forjando uma sociabilidade ao mesmo tempo rigidamente determinada pelo mercado e livre para, apenas no interior do mercado e do Estado, prover sua própria reprodução. 
Impelidas a acumular crescentemente capital, classes dominantes e seus prepostos concebem este mundo e sua própria necessidade de reprodução ampliada do capital como decorrentes da natureza das coisas e dos homens. Consciente ou inconscientemente, pois, impõem ao conjunto da sociedade a condição concreta para a naturalização de tal concepção, isto é, a generalização acelerada das expropriações primárias, aquelas que expulsam trabalhadores rurais dos campos ou os impelem às cidades.

Segundo os períodos e os países, a configuração dos setores de ponta, ou predominantes, das classes dominantes capitalistas se alterou: no século XIX, passamos do burguês enriquecido hesitante de sua posição social (Dobb, 1981; Hirschmann, 1979) ao capitão da indústria e ao banqueiro do século XIX, descritos de maneira brilhante pela literatura, de Balzac a Thomas Mann; com a monopolização na passagem do século XX, emerge a figura dos grandes capitalistas associados, com grandes impérios familiares expandindo a importância dos subcapitalistas - extratores de mais-valor, capitalistas funcionantes, ou gestores (Lênin, 1975), até a configuração atual, na qual classes dominantes de perfil difuso detêm o controle dos recursos sociais de produção sob forma monetária, de propriedade altamente concentrada e com crescente alcance internacional. Antes, como agora, a lógica do capital - cuja consciência fundamental é de que sua 'natureza econômica' necessita de maneira imperativa multiplicar-se - se apresenta como uma representação imediata do todo, como um espelho da natureza humana determinista e, ao mesmo tempo, como um modelo a ser alcançado pela totalidade da população. Já contraditórios entre si, esses determinismos se apresentam ainda como se decorressem de uma vontade livre.

Consciente ou inconscientemente, tais classes dominantes expandem as contradições nas quais elas próprias se debatem. Conscientemente impulsionam, segmentam e matematizam as expectativas de lucro através da reprodução do capital; mais ou menos inconscientemente (a rigor, de maneira cada vez menos inconsciente e com maior teor manipulativo), precisam expandir as relações sociais que as sustentam. As expropriações primárias, ainda em curso, se multiplicam por novas formas de expropriação social, base social efetiva da determinação social capitalista. ${ }^{3}$

Ora, a própria existência desses mesmos setores dominantes, se reduzida a tal acumulação ilimitada, torna-se insuportável e precisa de outros elementos com os quais se legitime a aridez decorrente de tal lógica. Até a década de 1970, ainda que já bastante erodida, persistia a difusão publicitária de uma promessa civilizadora, expressa, sobretudo, na generalização do conhecimento pela educação massiva, na melhoria das condições de saúde, através de serviços públicos expandidos, na urbanização como urbanidade e no acesso a um mercado supostamente capaz de suprir o conjunto das necessidades básicas das populações. 
Em outros termos, a defesa do capitalismo calcava-se no binômio democracia e desenvolvimento, tendo o Fundo Monetário Internacional (FMI) e o Banco Mundial como seus arautos (Pereira, 2009). Decerto, já é evidente sua impossibilidade: a democracia política - o voto como única expressão da vontade num mundo determinista cuja base fundamental (o econômico) não estava em discussão (Wood, 2003) - não impedira o ato inominável da destruição de Hiroshima e Nagasaki; alguma urbanidade em alguns países custava a expansão da catástrofe social expropriadora sobre o planeta e uma crescente devastação ambiental.

A partir da década de 1970 e, em especial, dos anos 80, mesmo estas justificativas foram destruídas por dentro como 'desnecessárias'. Restou como trunfo central do argumento apenas o tema da liberdade. A liberdade dos detentores de extensos recursos concentrados em poucas mãos - aparecia então como a maneira ilimitada histórica e geograficamente de ampliar a acumulação, sem a contrapartida de qualquer formato social preciso.

Mesmo para estes setores dominantes, uma tal liberdade é incapaz de eliminar a fonte central de sofrimento (a imperiosidade naturalizada da acumulação), pois é ela também a fonte fundamental da amputação da própria liberdade. A contradição é insolúvel. A vida amputada torna-se a regra: são amputados de liberdade os que não detêm os recursos necessários para uma liberdade amparada no mercado e na acumulação; mas são também amputados os que detêm os recursos necessários, pois, em primeiro lugar, sua liberdade é ineficaz para alterar sua própria limitação; em segundo lugar, sua liberdade real, garantida pela acumulação e pela propriedade de recursos sociais extraordinários, esbarra num mundo crescentemente desfigurado socialmente, no qual suas eventuais 'altas' expectativas são sempre frustradas e frustrantes; por fim, se as promessas entrevistas pela liberdade real, porém limitada, dos que detêm o capital são irrealizáveis, tendem a constituir-se como um terreno do futuro sempre por vir, acantonando-se num discurso duplo: o da absoluta impossibilidade do 'não há alternativa' tornado gêmeo com o 'tudo é possível'.4

Um eventual sofrimento das classes dominantes não nos interessa nem constitui o nosso objeto. Mencioná-lo nos permite, não obstante, entrever a impossibilidade crescente de que dessa lógica possa derivar qualquer perspectiva efetiva de futuro para o conjunto da vida social, pela incrustação do determinismo como seu elemento primário, primordial condição de sua existência como classe dominante e como forma de ser social, o que vem acoplado com sua reiterada negação impotente.

Se o determinismo econômico, através da fórmula popular 'não há alternativa', foi brandido nas últimas décadas de forma explícita, até mesmo espantosa, considerando-se a lógica capitalista dominante há vários séculos, o solo no qual se implanta é o mesmo de onde brota o amplo espectro quase 
esquizofrênico dos pós-modernismos, uma vez que estes se apresentam como o seu aspecto complementar, como o 'tudo é possível'.

Ora, das contradições efetivas da vida social contemporânea, dada a generalização do predomínio mundial do capital sob forma monetária e das expropriações que impõe, emergem inúmeras reivindicações e solicitações, impulsionadas por urgências variadas. Demandas e lutas por habitação, saúde, educação, transporte, emprego, salários, reconhecimento social (mulheres, sexualidade e questões étnicas), defesa de características tradicionais ou culturais, lutas antirracistas, defesa do ambiente ou de uma alimentação 'limpa' etc.; por mais amplas e variadas que sejam, fazem parte do extenso rol de modalidades pelas quais se expressam populações e grupos sociais de maneira mais ou menos imediata, isto é, voltadas para questões graves, porém segmentadas, do conjunto das demais relações nas quais tomam forma. Expressam, pois, formas de consciência - e não apenas 'identidades', embora as abarquem - fundamentais, não redutíveis umas às outras e raramente excludentes.

Constituem-se em modalidades emergenciais, que demandam respostas urgentes. Assim, podem ser canalizadas pelo aceno de 'tornar algo imediatamente possível', imediatamente passível de se converter em efetividade, mesmo se de maneira incompleta ou parcelar. Duas formas aparentemente distintas de determinismo se antepuseram a tais reivindicações.

Em primeiro lugar, no âmbito socialista, a suposição de que a luta de classes - ou, nos termos em que foi empregado, o movimento operário estaria baseada em relações econômicas (e/ou contratuais) imediatas, isto é, na suposição da adscrição da relação de classes à maneira imediata pela qual se organiza a grande empresa industrial capitalista e a relação empregatícia que nela vigora. Essa concepção ignora o fato de que capital, para tornar-se uma 'relação econômica', precisa moldar a organização da totalidade da vida social, precisa produzir trabalhadores 'livres', isto é, disponíveis física e psicologicamente. Ao reduzi-la à 'relação explicitamente econômica', tal formulação incorporava um elemento fundamental da justificativa ideológica do próprio capitalismo, ou seja, a suposição da separação entre economia e o restante da existência. ${ }^{5}$

Esse argumento encontrava assim a segunda vertente de determinismo, o naturalista, e o alimentava: a que se origina com a própria formação histórica do capitalismo e que, com escassa alteração de seus termos fundamentais, desemboca na convicção - reforçada pela queda real dos países do antigo bloco socialista - de que não há alternativas (pois teria sido derrotada a única opção viável, isto é, realizada) e que pensar a transformação social se inscreveria no campo de utopias ou não lugares. Em outros termos, um 'outro mundo' (a revolução) se inscreveria num terreno onírico, próximo do campo de desejos sempre impossíveis de satisfazer, sem qualquer 
apoio na forma real sobre a qual assenta a própria realidade histórica, assim naturalizada. Decerto, não há nesse âmbito uma homogeneidade teórica, expressando-se nessa posição desde filósofos liberais 'duros', como Hayek ou Friedman, até diversos 'novos filósofos' convocados para difundir essa suposta impossibilidade, dentre eles Fukuyama. Nestes casos, o determinismo econômico é explícito, sempre formulado em termos de 'natureza humana'.

Por seu turno, a recusa genérica dos determinismos, ao não recolocar a exigência da compreensão das formas históricas da determinação do conjunto da vida social, conduziu ao abandono da proposição socialista anterior - frágil e inconsistente teoricamente, com certeza 6 -, mas também desconsiderou as modalidades concretas da totalização real da vida social. 7 Tal procedimento assumiu variados formatos, por exemplo, em Foucault e Habermas. Muitos de seus seguidores, em extensas áreas da sociologia e das diversas ciências sociais, sentiram-se 'livres' de tal peso - o peso próprio do conhecimento, o de explicar e compreender as formas efetivas da unificação crescente do mundo social sob o capital - e passaram a dedicar-se a aprofundar análises, embora algumas delas sérias, sobre temas a cada dia mais pontuais e segmentados. 8

Compreende-se que, em alguns casos, tais análises segmentadas correspondiam ou aproximavam-se de interesses e necessidades reais e prementes, mais ou menos imediatas, de inúmeros setores sociais, sobretudo em caráter emergencial. Podemos compreender por que esse conjunto díspar de reflexões, genericamente designado como pós-moderno, mesmo contendo muitas nuances em seu interior, tornou-se uma muleta teórica para muitos movimentos sociais e partidos políticos que, permanecendo formalmente anticapitalistas, passaram a atuar - intelectual e praticamente - na urgência legítima de oferecer socorro a inúmeras situações dramáticas em curso, abandonando os elos que atavam tais premências ao conjunto da existência social.

Explicitamente, no primeiro caso, os liberais deterministas, e implicitamente no segundo, os antideterministas imediatistas ou pragmáticos, adotava-se uma única definição de natureza humana: aistórica, não constituída por relações mais extensas do que as imediatas. Desconsiderava-se a consciência, suas contradições, sua historicidade e suas possibilidades e sua relação substantiva com o mundo social, substituída pela identidade (rapidamente apresentada no plural, no qual somavam-se características díspares, sem incorporar suas contradições). Convertia-se a cultura em espécie de cápsula envolvente e inflexível, esvaziando-a de seu caráter social, porém desigualmente compartilhado e, portanto, cegando-a para o futuro e as transformações de que é portadora. O horizonte da existência humana era reduzido às dimensões de cada vida singular, encapsulada em sua solidão, biológica, cultural e/ou identitária. 
O abandono do terreno da reflexão sobre a determinação confortou, portanto, um dos determinismos mais violentos e mais difundidos já experimentados historicamente, posto que atravessava agora áreas social e politicamente muito diversificadas.

\section{O que é econômico?}

Ora, a única sociedade, historicamente falando, diretamente regida pelo econômico é a capitalista. Somente nessa configuração de classes o econômico é erigido prática, social e intelectualmente como entidade externalizada, é vivido e experimentado de maneira naturalizada e essa imposição se apresenta como se tivesse caráter permanente e eterno. Tragicamente, desde seus primórdios, seus ideólogos procuraram cravar intelectualmente tal característica na própria natureza humana, convertendo o que é sua peculiaridade histórica (e transitória) própria em determinismo abstrato da existência humana (Fontana, 1982). A condição histórica do capitalismo se converte, tanto na dimensão intelectual quanto na existência concreta e singular (de cada um de nós) sob tal configuração, em determinismo absoluto.

Essa característica confere à sociedade capitalista a capacidade de resumir todas as explorações de classe pregressas, condensando-as tanto na abstração de um pensamento naturalizante quanto na prática ao extorquir os seres singulares de suas condições sociais prévias - relembramos que reexpropriações podem ocorrer também no interior de sociedades plenamente capitalistas e desenvolvidas -, para reduzi-los a uma situação similar à de pura natureza frente à existência social. O ingresso numa nova sociabilidade, multilateral e extensa, dadas as dimensões da divisão internacional do trabalho e, sobretudo, da cooperação real entre os trabalhos, é sempre reconduzido a um papel menor frente à condição fundamental de expropriação.

A imposição social de dispor apenas da força de trabalho para subsistir, em uma duríssima realidade penosamente construída, resultante de múltiplas expropriações, se converte em 'necessidade humana'. O determinismo econômico é capaz de, assim, assegurar um duplo movimento: dizer a verdade e ocultá-la. O econômico determina a vida social sob o capitalismo, o que é verdadeiro, pois, se predomina o capital, essa relação social se lastreia sobre a exigência diretamente econômica da acumulação, subordinando todas as subsistências singulares ao mercado. Simultaneamente, oculta a historicidade e maleabilidade social, obscurecendo-as sob a suposição da eternidade de tal característica.

Esse discurso elimina a multiplicidade das relações sociais reais - a vida concreta, a humanidade real, a totalidade - e coloca na frente da cena um 
ser singular isolado, defrontado com suas necessidades biológicas e temeroso das relações sociais (estranhadas), sem as quais não pode existir. Formam-se seres singulares cindidos não entre alternativas, mas pela dupla inexistência de alternativas.

Karl Marx foi muitas vezes acusado de economicismo ou de ser a origem de um determinismo com base no econômico. Há, inclusive, um enorme debate intelectual sobre o que significa 'determinação em última instância' pelo econômico, convertido em alguns casos em polêmicas aistóricas. Ora, Marx realiza uma funda crítica da economia, pois nela identifica exatamente o cerne da dominação capitalista. A meu juízo, podemos, a partir de Marx, abandonar qualquer modalidade de determinismo, sobretudo o econômico, ao mesmo tempo que adquirimos as bases para compreender as determinações - históricas, objetivas e subjetivas, inclusive econômicas da vida social contemporânea.

Somente na sociedade capitalista moderna o econômico surge como instância decisiva, central e isolável da existência social. Pela extensão das relações sociais nas quais o capital se apoia, permite desvendar - com a condição de que se evite cuidadosamente todo o anacronismo - o que se ocultava sob as formas aparentes (religião, racismo etc.) da exploração de classes em modos anteriores. O capital repousa, porém, não em seus argumentos justificadores, nem na pretensa ciência que fomenta a economia, cujo objetivo é assegurar o crescimento da riqueza dos proprietários, mantendo-se as condições sociais dadas. Certamente, o capital depende da capacidade da extração sempre ampliada do sobretrabalho sob a forma da mais-valia, isto é, exploração de trabalhadores formalmente livres, e, como é essa a forma dominante que o sustenta, as explicações 'deslizam da evidenciação da condição social' na qual se baseia 'para a atividade' predominante da qual depende sua própria reprodução como forma de vida social, a acumulação ampliada ou o mais-valor. Deixa, pois, na sombra o elemento central: o capital baseia-se na permanente ampliação e exasperação de uma 'certa relação social' - a disponibilização massiva, tendencialmente atingindo toda a população, dos seres singulares convertidos em necessidade, em disposição única para a venda de força de trabalho sob quaisquer condições, base social para que de um mercado 'econômico' supostamente livre possa se generalizar. 'A expropriação massiva é condição inicial, meio e resultado da exploração capitalista.'

Do determinismo econômico abstrato, que parece pairar aistoricamente sobre as sociedades humanas, chega-se a uma determinação fundamental, que nada tem de determinista e está banhada na história: a própria organização da vida social, tomada concretamente, é a base material - a determinação - fundamental sobre a qual pode se assentar o conhecimento social. 


\section{Marx e a determinação}

Não está presente em Marx a suposição de que uma tal marca histórica dramática - uma economia como instância com uma dinâmica própria - precise ser preservada ou, pior ainda, configure uma 'condição natural' que, ao mesmo tempo que se expande, se aprofunda como escassez premente. $\mathrm{O}$ tema da determinação econômica, em Marx, remete a dois fatores que merecem ser abordados em conjunto, embora expressem determinidades distintas.

Em primeiro lugar, a vida biológica somente pode ser assegurada se for materialmente reproduzida, assegurando-se na troca metabólica com a natureza a reprodução da própria existência, em suas condições elementares, biológicas. Aqui reside uma 'determinação primeva' de todas as existências biológicas, compartilhada, portanto, com as demais espécies animais. Ainda nesse terreno elementar, as diversas espécies enfrentam as próprias transformações que acarretam na natureza, assim como as transformações que, advindo sem intervenção direta delas, decorrem de circunstâncias naturais

- formas de adaptação e transformação ligadas à própria evolução das espécies, sem qualquer correlação com alguma consciência deste processo pelas espécies concernidas (Tort, 1983). O pensamento economicista, ao desconsiderar a historicidade e a socialização, inclusive as sociabilidades diversas que promovem, crava aqui seu determinismo, agregando uma consciência humana impotente a uma natureza implacável.

Em segundo lugar, a reprodução humana, isto é, social e histórica, incorpora, para além das necessidades primevas ligadas a esse metabolismo (o qual, de forma alguma, é fixo e cristalizado), diferentes necessidades outras, historicamente construídas, todas resultantes da atividade social e do trabalho. Ao converter-se em 'trabalho', ao humanizar-se, essa atividade se diferencia radicalmente da atividade primeva, ainda que incorpore sua exigência primordial, a da sobrevivência.

O trabalho, ao permitir o crescimento da capacidade produtiva social, altera a relação metabólica com a natureza - aprofundando-a, multiplicando-a e convertendo-a em fenômeno diretamente social. Altera também o 'modo de ser', o modo de produzir-se como seres sociais e singulares. Porém, ao serem ao longo da história privadamente apropriadas as condições para o exercício do trabalho, erige-se um enorme obstáculo para que tais possibilidades sociais reais convertam-se em efetividades coletivas igualitárias.

Um de seus resultados, dramático, é o permanente bloqueio assim instaurado à emergência de verdadeiras e extensas diferenciações singulares ou, em termos mais usuais, de uma plena individualização, uma vez que a ela se superpõe uma cristalização social constante e crescente, hierarquizando as diferenciações 'coletivas' prévias, expressas, por exemplo, nos racismos, nas discriminações diversas etc., e os atributos 'singulares', aos quais, 
além dos obstáculos anteriores, se acrescenta a concorrência, homogeneizadora e hierarquizante por excelência.

Antes de retomar o tema da determinação, paremos rapidamente numa duplicidade do conceito de trabalho, de forma a melhor explicitar a redução econômica ou economicista e sua superação por Marx.

\section{Trabalho}

Partindo, sobretudo, dos escritos do jovem Marx, mas recorrendo extensamente à sua obra madura, como O Capital, Lukacs desenvolve e consolida uma reflexão que faz repousar sobre o trabalho a própria humanização da humanidade, base do processo através do qual seres de uma certa espécie convertem-se em seres humanos, sociais. Sua ontologia do ser social assinala um salto ontológico na constituição da própria espécie, ruptura essencial que conserva as características biológicas compartidas com as demais espécies naturais, porém da qual resulta uma nova espécie, com características qualitativamente novas, todas elas plenamente sociais - linguagem, socialização, consciência, divisão do trabalho etc. (Lukacs, 2004). Atribuindo a Engels o mérito de elevar o trabalho ao centro do processo de humanização do homem, Lukacs desenvolveu extensa e profundamente a importância de tal centralidade, sobretudo através da posição teleológica (causalidade posta) realizada por meio do trabalho. Recusando liminarmente modelizações mecânicas, afirma que "o trabalho pode servir de modelo para a compreensão das demais posições teleológicas sociais, já que o trabalho, de acordo com seu ser, é a forma originária (Urform) de todas essas posições"' (Lukacs, 2004, p. 62).

Desse ponto de vista, a atividade criativa, criadora e autotransformadora, da qual o trabalho é a protoforma, caracteriza a humanidade no seu sentido mais pleno. Em outros termos, as demais atividades dele derivadas - e para as quais o trabalho segue sendo a protoforma -, como a ciência e a arte, por exemplo, são seus desdobramentos intrínsecos, e não extrínsecos. Em qualquer sociedade de classes, ocorre uma dupla divisão social hierárquica do trabalho - horizontal e vertical - que corresponde a um agenciamento especial da vida social, uma forma específica de distribuição dos seres singulares e de suas atribuições. Essa divisão impõe uma cooperação falseada e, com isso, todos os seres singulares se veem fadados a perder parcela de si mesmos.

Lukacs desenvolve ainda extensa crítica às limitações das epistemologias que abandonam os pressupostos ontológicos, exatamente por fazerem desaparecer a relação entre humanidade e trabalho; e, no trabalho, as conexões entre valores e conhecimento, explicitando a íntima relação entre práxis social (cujo modelo é o trabalho) e valores, ${ }^{9}$ ainda que estes sejam sempre relativos às condições históricas nas quais se explicitam. 
Essa abordagem retoma decisivamente um dos sentidos do trabalho realizado por Marx. Não elimina, entretanto - embora não se debruce especificamente sobre ela -, um outro sentido, mais diretamente histórico, ou desdobramento histórico dos processos sociais de trabalho, que também lhe atribui Marx.

Em um segundo sentido atribuído por Marx ao trabalho, este, como forma genérica dos seres humano reais e concretos, portanto sociais, é recente e corresponde plenamente apenas à sociedade capitalista. Somente pôde ser compreendido como trabalho, em seu sentido mais amplo, a partir da existência concreta da relação social capitalista, que produz seres sociais disponíveis (e necessitados) num mundo mercantil e que os subordina massivamente à potência unificadora - e exploradora - do capital.

O trabalho parece ser uma categoria muito simples. E também a representação do trabalho neste sentido geral - como trabalho em geral - é muito antiga. Entretanto, concebido economicamente nesta simplicidade, o 'trabalho' é uma categoria tão moderna como o são as relações que engendram essa abstração (Marx, 1985).

As relações sociais impostas pela dinâmica capitalista exacerbaram o que já estava presente em sociedades anteriores também baseadas na exploração - separação entre trabalho intelectual e manual; entre refinamento intelectual e vida material; e imposição de todas as tarefas fundamentais do intercâmbio com a natureza para as classes subalternas (Marx e Engels, 2007).

Diferentemente das sociedades anteriores, o capitalismo pôs a nu uma plenitude maior de suas características e contradições: a imposição da necessidade imperiosa da subsistência como forma social, e não apenas 'natu$\mathrm{ral}^{\prime}$, dominante; a faculdade socialmente humana de produzir mais do que o necessário para sua sobrevivência, explicitada sob o capital ao ser convertida de possibilidade permanente de transformação da existência em acumulação ampliada concentrada e, portanto, em forma de sujeição e recorrência obsessiva; e a generalização da cooperação entre massas crescentes de seres singulares, os trabalhadores, através de uma socialização efetiva do processo social de trabalho, em todos os níveis (local, nacional e internacional) e setores, contraposta ao rígido e hierárquico controle dos recursos sociais de produção, secretando desigualdades por todos os poros.

A contradição assim explicitada aponta os elementos sociais objetivos capazes de impulsionar uma atuação objetiva e subjetiva para sua superação: a tendência à redução de todas as formas da atividade à produção de mais-valor, subordinando-as à exploração do capital, evidencia o quanto uma formidável e variada gama de atividades integra socializadamente o complexo fenômeno do trabalho.

Poderíamos procurar resolver de forma aparente a duplicidade do trabalho: por ser a forma prévia ou originária do ser social, o que implica ser 
histórico, o próprio trabalho, ao expandir-se socializadamente, se desdobraria ulteriormente em 'outras' formas e, portanto, seu próprio desenvolvimento poderia conduzir à perda de sua centralidade, que seria doravante atributo de outras esferas - superiormente elaboradas - do ser social.

Não pretendemos, entretanto, optar por essa via. Ao contrário, parecenos fundamental não reduzir o problema à opção por um ou outro sentido. Em algumas situações, o conhecimento pode explicitar-se menos através de uma solução, e mais pela recolocação do problema. Trata-se de compreender em que medida a sociedade capitalista, ao desenvolver de forma extremada a subordinação do trabalho ao capital, faz emergir ao mesmo tempo o trabalho como o fundamento da humanização - da historicidade, do conhecimento, da linguagem, da consciência, dos valores - e desfigura a humanidade concreta, ao desqualificar o trabalho, tornando-o incompreensível, estranhado e abjeto. Somente uma forma superior de organização da vida social pode, ao mesmo tempo, conservar e expandir as inúmeras modalidades sociais que o trabalho pode recobrir em uma cooperação igualitária e eliminar o ranço histórico de sua divisão hierárquica e subalternização à propriedade dos recursos sociais de produção.

Marx aponta, entretanto, como foi exatamente por intermédio do pensamento econômico que as condições dessa explicitação vieram à luz, quando a economia política apontou - com muita dificuldade e muitas ambivalências - que o trabalho em geral, trabalho sem adjetivos, é a fonte de toda a riqueza.

Um enorme progresso se deve a Adam Smith, que rejeitou toda determinação particular da atividade criadora de riqueza, considerando apenas o trabalho puro e simples. Com a generalidade abstrata da atividade criadora de riqueza, igualmente se manifesta então a generalidade do objeto determinador da riqueza, o produto em absoluto, ou, ainda, o trabalho em geral, mas como trabalho passado, trabalho objetivado (Marx e Engels, 2007).

Interessa-nos aqui ressaltar o duplo passo dado pela economia política burguesa ao identificar o trabalho como 'riqueza' ou 'fonte de riqueza': aponta efetivamente para a condição social real na qual repousa a economia capitalista, ao defini-lo não por sua atividade efetiva de socialização humana (o que inclui tanto a reprodução primeva quanto a produção necessária de novas e mais extensas e/ou elevadas possibilidades), mas unicamente pela sua característica 'econômica', inaugura uma economia como conhecimento apartado da humanidade que o elabora e instaura.

Voltemos agora ao tema da determinação. 


\section{Cisão social e intelectual dos determinismos}

Sob o capitalismo, as duas condições de reprodução, a primeva e a históri$\mathrm{ca}$, aparecem como cindidas, o que consolida um rígido determinismo no qual o biológico é travestido em 'econômico', como se o elemento natural da condição essencial da existência biológica negasse o processo propriamente humano, social e histórico de realização, produção e reprodução, de fato, dessa existência. Ora, o processo histórico expressa enorme impulso de socialização concreta da reprodução das condições da existência (o desenvolvimento das forças produtivas), ainda magnificadas sob o capitalismo, uma vez que aqui se põe em marcha uma tendência a converter toda a população mundial em força de trabalho disponível e todas as atividades em modalidades variadas de extração de mais-valor. Essa cisão, sempre de forma ambivalente, recoloca uma 'natureza humana' a ser permanentemente petrificada - a necessidade da subsistência biológica devendo sobrepor-se às condições sociais e socializadas de produção e de reprodução.

Contraditoriamente, quanto mais a produção da existência torna-se amplamente socializada, como resultado propriamente histórico, inclusive em escala planetária, excedendo exponencialmente as necessidades primevas na sua produção, tanto menos garante a satisfação de tais necessidades.

A apropriação privada dos excedentes sob o capitalismo exerce enorme pressão sobre massas crescentes de trabalhadores livres, a serem permanentemente desapropriados, despossuídos do caráter histórico da vida social e mantidos em uma dupla condição de necessidade premente: a da reprodução imediata, metabólica, com a natureza, contraposta a uma produção social sempre mais socializada. O desemprego ou mesmo sua ameaça e, mais recentemente, a inexistência de relação contratual empregatícia, exercem essa função violenta de maneira direta, impondo um rígido determinismo das condições naturais através das relações sociais, apresentando-a como perene.

A contínua abertura de possibilidades se converte também continuamente na produção da escassez e da existência mutilada. Crescem - e não recuam - as impossibilidades cindidas (mas somadas) do acesso aos frutos sociais do trabalho e da atividade humana, resultantes tanto das necessidades primevas quanto de crescentes necessidades socialmente construídas. A ânsia primordial de reprodução biológica (metabolismo coletivo primário com a natureza) é permanentemente reinstaurada e reafirmada de maneira isolada, exatamente quando todas as condições históricas mostram a evidência da socialização como elemento determinante da vida social.

Sob uma dinâmica destroçadora da humanidade, as próprias necessidades historicamente construídas tornam-se destrutivas 10 até mesmo das condições biológicas de existência, como a produção de artefatos nucleares capazes de eliminar a própria existência humana, de desfigurá-la biologica- 
mente, com alimentos cancerígenos ou através de patentes de vida humana, retroalimentando seu determinismo constitutivo através de formas ainda mais complexas de expropriação. ${ }^{11}$

Tal configuração social aprofunda a cisão característica das sociedades de classe, amplificada pela escala da reprodução capitalista, na qual a reafirmação cotidiana da determinação primeva, natural, imposta não apenas pela própria natureza, mas sobretudo pela apropriação privada das condições sociais de reprodução, se duplica pela reafirmação discursiva de uma liberdade abstrata.

Assim, ao rígido determinismo econômico naturalizado - isto é, à exigência e imposição da reprodução das condições de apropriação privada dos excedentes sociais - se acoplam, por razões sociais e intelectuais diversas, a suposição de uma liberdade abstrata, sem qualquer correspondência com a libertação de condições reais. A vida concreta e suas condições efetivas parecem flutuar como 'anexos' aleatórios, resultantes de uma pura necessidade objetiva e natural que se tornaria, pela liberdade truncada e pela consciência cindida, integralmente subjetiva. Abre-se assim o terreno da pura arbitrariedade, traduzida como exercício de vontades que, ao não alterar as relações substantivas, materiais e subjetivas, entre os seres sociais, ou seja, sua distribuição e organização na produção da integralidade da existência social, atua seja mitigando os efeitos sociais, seja expressando uma raiva impotente. 12

Ora, a que condições reais, históricas e concretas Marx nos incita a compreender e explicar? O que, segundo ele, diferencia os períodos históricos, os modos de produção ou, mais precisamente, as 'formas de modos de ser' sociais? Se a determinidade primeva da necessidade permanente de uma troca metabólica com a natureza atravessa todos os momentos históricos, ela não pode se constituir em diferenciador desses distintos períodos históricos. Também não seria a materialidade externalizada das coisas produzidas o que define o processo sócio-histórico, nem a permanência genérica da necessidade historicamente construída de satisfação de tais necessidades, necessidade que constitui a própria humanidade. A primeira integra o solo biológico no qual se plasmam todas as espécies. Esta espécie humana, social e histórica, entretanto, produz não apenas o metabolismo coletivo com a natureza, o que ocorre também em outras espécies, mas reintegra a experiência derivada dessa atividade (trabalho) à sua própria configuração. Ela é permanentemente plástica, histórica, alterando-se com as transformações que provoca e incorpora.

Assim, é exatamente a forma social, propriamente humana, de superar de maneira coletiva tal determinidade imediata, incorporando-a e elaborando-a não apenas como um imperativo natural, mas como uma forma de existência peculiar que constitui a determinação em Marx. A rigor, ela aponta 
para um elemento de irretorquível liberdade - concreta, simultaneamente social e singular -, pois, ao incorporar o elemento natural sob a forma social real na qual vive, torna-se capaz de superá-lo, isto é, de apaziguar coletivamente necessidades singulares, moldando-as e reconfigurando-as. Tal definição transborda o que se chama econômico na vida atual, embora o incorpore e faça sua crítica.

O que constitui o substrato concreto e material, o fundamento crucial da determinação social tal como aponta Marx? Ora, o processo histórico corresponde à construção de 'formas tão concretas e palpáveis de relações e seres sociais - distribuição dos seres singulares no processo de reprodução da existência coletiva - quanto à materialidade primeva da necessidade da troca imediata com a natureza para a subsistência'.13

Somente no interior de relações autotransformadoras coletivas, sociais, o gênero humano pode realizar tal troca metabólica. Nesse sentido, o conjunto dessas relações, atuais e pregressas, constitui-se como sua própria natureza - sua 'segunda', porém primordial natureza -, uma vez que fora dele a determinidade precedente, primeva, não pode realizar-se. Estamos falando, pois, de uma característica 'não biológica, ainda que conserve os elementos biológicos como condição de possibilidade' - a historicidade - que somente pode ser compreendida se levar em consideração seu aspecto imediatamente social e plástico, o qual desde sempre incorpora sua realidade corpórea, biológica. Social, pois não deriva apenas de uma imediaticidade das condições orgânicas que, embora subsistam, necessariamente incorporam uma forma coletiva específica, diferente segundo o grupo social e o período histórico, e agregam elementos - construídos pela própria humanidade - de satisfação (ou de escassez) e que fazem com que as próprias necessidades primevas somente possam ser satisfeitas no contexto de tais relações.

A historicidade não se constitui como algo externo aos seres singulares, mas, ao contrário, como algo interno, como sua mais própria 'natureza'. Ora, os humanos partilham algumas características com inúmeras outras espécies, aquelas cuja existência depende de formas organizadas e coletivas de produção da subsistência. Trabalho humano e social é, desde sempre, algo a mais do que a atividade voltada para assegurar a imediaticidade da subsistência - se realiza sob, exige e impõe uma reprodução de condições sociais, coletivas, de tal processo, através de atividades mais variadas, integrando a consciência da abertura para o futuro, pois incorporadora das atividades pregressas.

Nesse ponto, encontramos a forma especificamente humana do trabalho, que não se limita ao aspecto natural de assegurar a subsistência, posto que gera infinitas novas possibilidades e necessidades, nem ao fato de ser atuação coletiva, o que pode ser encontrado em outras espécies. Para além desse quadro ou contexto coletivo, sua especificidade deriva da socializa- 
ção do trabalho como construção de relações históricas, moldáveis, nas quais o aprendizado de processos anteriores seja integrado como repertório - possível e/ou necessário14 - dessa mesma espécie. Com isso, a atividade da produção social da vida 'conserva' os elementos biológicos, assegurando a reprodução da espécie, ao passo que reduz a determinidade primeva que, de imposição abstrata, converteu-se em forma social; 'incorpora' as múltiplas experiências singulares como modalidade coletiva; e, finalmente, torna-se capaz de 'convertê-las' - ou não15 - em sua forma específica de ser.

Estamos diante de uma espécie cuja reprodução singular, ou seja, a preservação de cada singularidade biológica, somente pode assegurar-se como parte ou parcela da reprodução do conjunto social imediato, o que significa um quadro mais complexo de reprodução e de organização. Para além disso, a atividade humana converte-se em algo mais do que simples reprodução biológica ou coletiva: trata-se de uma reprodução que incorpora as aquisições anteriores e que as modula, podendo reinventar-se, modificar-se ao reproduzir-se. Em outros termos, é um processo que gera singularidades capazes de alterar os procedimentos herdados e de coletividades capazes de experimentar novos procedimentos trazidos pelos seres singulares. Reúne sempre os dois elementos. Em outros termos, uma coletividade cuja existência caracteriza-se pela possibilidade de alterar-se ao longo do tempo, histórica.

Em que consiste, pois, a materialidade das relações sociais e, portanto, da determinação histórica em Marx? De forma alguma poderia residir num econômico reduzido à mera expressão da necessidade biológica primeva. Embora esse elemento seja 'alçado de forma contraditória' pelos ideólogos do capitalismo à condição 'natural' humana, trata-se de um reducionismo que converte em justificativa a sujeição real que as relações sociais capitalistas realizam na prática, ao expropriar permanentemente os trabalhadores de suas condições de reprodução, impondo-lhes de fato e realmente a exigência da reprodução biológica como se constituísse uma exigência unicamente singular, como se estivessem num mundo de seres isolados.

A materialidade das relações sociais reside no agenciamento e na forma de organização - e de ser - que em cada momento histórico resulta de atividades precedentes e preside a forma coetânea de sua realização. A isso, Marx chamou de modos de produção ou de "formas de modos de ser" (Marx, 1985, p. 121), enfatizando a distribuição dos seres sociais no processo pelo qual, em cada período histórico, se garante o conjunto de atividades que assegura a produção da existência em sua integralidade (biológica, social, cultural etc.). A própria determinidade primeva somente assume sentido e existência no quadro das relações sociais, coletivas, nas quais efetivamente se realiza e se concretiza.

Aqui, pois, 'a determinação do econômico' - agora de forma refletida, pensada - se expressa de maneira mais compreensível. Trata-se de uma 
forma específica e histórica de dominação de classes, socialmente avassaladora num mundo cujo predomínio do capital tornou-se generalizado. Não se trata de considerar que tal determinação seja um elemento da própria natureza humana ou social, posto que já assinalamos os elementos da socialização e da historicidade que as reveste. Essa determinação do econômico não se explica por si mesma, mas repousa sobre uma forma de ser social específica, a massificação e diversificação das expropriações, ou seja, a produção de seres singulares disponíveis e necessitados de mercado, base fundamental para que a exploração propriamente econômica do capital possa impor-se. Enquanto houver capital, o econômico exercerá uma funesta exasperação de tais relações sociais e, por seu turno, se apresentará como necessidade natural e incontornável. O desafio que nos coloca é o de identificar como a determinação social converte-se em econômico. Por isso, a importância da compreensão atual das formas econômicas, modalidade específica e totalizadora, sob o capital, da dominação de classes; mas, mais importante ainda, a exigência da plena compreensão da forma específica de ser social.

A determinação, em Marx, não é redutora e, portanto, não repousa sobre um econômico entificado. Não remete a nenhum elemento externo aos seres sociais, como uma 'economia' e, menos ainda, a uma natureza reificada como elemento agressivo e internalizado. Ao contrário, repousa sobre o que nos constitui como seres sociais e singulares e, portanto, assinala a urgência de nos defrontar coletivamente contra uma forma social que pretende bloquear nossa historicidade constitutiva.

\section{Agradecimento}

Agradeço a Carla Macedo Martins, pela revisão amiga.

\section{Notas}

I Integrante do Grupo de Trabalho em Epistemologia da Escola Politécnica de Saúde Joaquim Venâncio, Fundação Oswaldo Cruz (EPSJV/Fiocruz). Professora do Programa de Pós-Graduação em História da Universidade Federal Fluminense (UFF). Colaboradora da Escola Nacional Florestan Fernandes (ENFF-MST). Doutora em Filosofia pela Universidade Paris X. <vfontes@superig.com.br>

Correspondência: Fundação Oswaldo Cruz, Escola Politécnica de Saúde Joaquim Venâncio, Avenida Brasil, 4.365, Manguinhos, Rio de Janeiro, Brasil, CEP 21040-900.

2 Esta comunicação resulta de pesquisa com o apoio do Conselho Nacional de Desenvolvimento Científico e Tecnológico (CNPq). Devo enormemente ao Grupo de Trabalho e 
Orientação (GTO), composto por orientandos, que, muito mais do que isso, são companheiros, interlocutores e amigos, pelos longos encontros e debates rigorosos sobre o tema.

3 Em outros trabalhos, apresentei algumas características das novas expropriações, secundárias: a dos direitos sociais e, sobretudo, daqueles coligados ao processo de trabalho, além da expropriação de bens coletivos, como águas, sementes, produção intelectual etc. Ver também Harvey, 2004.

4 Koyré destaca, para um período de transição histórica - a Renascença -, a situação na qual a perda das referências ontológicas precedentes, tomistas (considerada a ontologia como a maneira pela qual se pensava o ser social e o próprio mundo), sem a correlata constituição de uma nova ontologia, que apenas paulatinamente se instaurava, gerou um processo no qual um verdadeiro 'naturalismo mágico' se generalizaria, com a suposição de que 'tudo era possível'. Ver Koyré, 1991, p. 46-55.

$5 \mathrm{O}$ que veio a ser reiterado de maneira brutal pelos que propugnavam a existência de três setores distintos e separados na vida social - o mercado (a economia, a técnica), a sociabilidade (a vida, a existência) e o Estado (a política, a ação coletiva).

6 Tais fragilidades e insuficiências foram longamente apontadas no interior da tradição comunista, por exemplo, por Antonio Gramsci, em especial em seus Cadernos do cárcere. Vale ressaltar que, em muitos casos, o frenesi de adesão ao liberalismo redundou em verdadeiras caricaturas do marxismo, mais fáceis e rápidas de descartar do que o estudo e a crítica consistentes.

7 O mais surpreendente é que este abandono teórico da noção de totalidade ocorreu ao mesmo tempo que se potencializava a concentração internacional de capitais sob a forma monetária, que impôs a ferro e fogo padrões comuns totalizadores - tensamente unificados - de exploração do trabalho em praticamente todo o planeta.

8 Esse formato se adequava bastante bem aos padrões concorrenciais científicos dominantes e os impulsionou ainda mais, pela redução enorme das margens de contestação e rebeldia no próprio interior dos meios de produção científica.

9 "A objetividade dos valores se baseia, pois, em que estes são componentes motores e movidos da evolução social inteira" (Lukacs, 2004, p. 151).

10 Falseia-se a própria produção de necessidades quando o imperativo da acumulação impõe a produção de lixo ou de desutilidades como condição de sua reprodução, como ressalta Mészáros, especialmente no capítulo 14, "A produção de riqueza e a riqueza da produção" (Mészáros, 2002, p. 605-633).

11 Neste caso, expropriação das condições naturais da reprodução agrária através de transgênicos (Lander, 2008; Garcia, 2006) e, ainda mais inquietante, o avanço extraordinário das expropriações da composição orgânica do ser humano, através de patentes humanas, o que suscitou inquietante reflexão de G. Agamben (Basques, 2008).

12 Isso conduz, muitas vezes, a que setores de forças populares pensem as condições de luta apenas como decorrentes da vontade social imediata, descolada das relações sociais concretas e dos sujeitos historicamente constituídos. A denúncia - legítima - dos arbítrios sociais e das injustiças perde de vista as condições efetivas, concretas e materiais da reprodução da vida social sob o domínio de classes sociais dominantes. 
13 Embora em outro registro teórico, vale a pena atentar para a materialidade estruturante que o conceito de habitus adquire em Norberto Elias ou Pierre Bourdieu.

14 Transformações advindas do processo de trabalho podem se converter quase imediatamente em necessidades coletivas - como vasos para transporte de líquidos, em tempos ancestrais, ou antibióticos, em tempos mais recentes - ou podem permanecer longo tempo em hibernação, como possibilidades abertas.

15 Transformações advindas do trabalho podem se converter quase imediatamente em necessidades coletivas ou, ao contrário, serem bloqueadas. Vejamos apenas dois exemplos: a decisão unilateral de classes dominantes sobre os processos de trabalho e sobre os bens a produzir descarta ou mutila novas e diversas possibilidades, de um lado, e, de outro, suscita formas de resistência social a inovações impostas.

\section{Referências}

BASQUES, Messias. Livros - The open: man and animal. Interface - Comunicação, Saúde, Educação, v. 12, n. 26, jul.-set. 2008. Disponível em: <www.scielo.br/scielo.php? pid=S1414-32832008000300018\&script $=$ sci_arttext>. Acesso em: 29 jul. 2009.

DOBB, Maurice. A evolução do capitalismo. 8. ed. Rio de Janeiro: Zahar, 1981.

FONTANA, Josep. Analisis del pasado y proyecto social. Barcelona: Grijalbo, 1982.

GARCIA, José Luiz. Biotecnologia e biocapitalismo global. Análise Social, v. XLI, n. 181, p. 981-1.009, 2006. Disponível em: $<$ www.scielo.oces.mctes.pt/scielo.php?pid $=$ S0003-25732006000400002\&script $=$ sci_arttext>. Acesso em: 29 jul. 2009.

GRAMSCI. Antonio. Cadernos do cárcere. v. 1. Rio de Janeiro: Civilização Brasileira, 2001.

HARVEY, David. O novo imperialismo. São Paulo: Loyola, 2004.

HIRSCHMANN, Albert O. As paixões e os interesses. Rio de Janeiro: Paz e Terra, 1979.

KOYRÉ, Alexandre. Estudos de história do pensamento científico. Rio de Janeiro: Forense Universitária, 1991.
LANDER, Edgardo. A ciência neoliberal. In: CECEÑA, Ana Esther (Org.). Os desafios das emancipações em um contexto militarizado. São Paulo: Expressão Popular/Clacso, 2008.

LÊNIN, Vladimir. L'impérialisme, stade suprême du capitalisme. Paris, Moscou: Sociales, Du Progrès, 1975.

LUKACS, Georg. Ontología del ser social: el trabajo. Buenos Aires: Herramienta, 2004.

MACPHERSON, Crawford B. La théorie politique de l'individualisme possessif. De Hobbes à Locke. Paris: Gallimard, 2004.

MARX, Karl. Para a crítica da economia política. In: MARX, Karl. Manuscritos econômico-filosóficos e outros escritos. 3. ed. São Paulo: Nova Cultural, 1985.

MARX, Karl; ENGELS, Friedrich. A ideologia alemã. São Paulo: Boitempo, 2007.

MÉSZÁROS, István. Para além do capital: rumo a uma teoria da transição. Campinas, São Paulo: Unicamp, Boitempo, 2002.

PEREIRA, João Márcio Mendes. O Banco Mundial como ator politico, intelectual e financeiro, 2009. Tese de Doutorado, Niterói: Universidade Federal Fluminense. 
THOMPSON, Edward Palmer. A formação da classe operária inglesa. 3 v. Rio de Janeiro: Paz e Terra, 1987.

TORT, Patrick. La pensée hiérarchique et l'évolution. Paris: Aubier, 1983.
WEBER, Max. Essais sur la théorie de la science. Paris: Pocket, 1992.

WOOD, Ellen M. Democracia contra capitalismo. São Paulo: Boitempo, 2003.

Recebido em 26/05/2009

Aprovado em 29/06/2009 